\title{
Significant Conformational Changes in an Antigenic Carbohydrate Epitope upon Binding to a Monoclonal Antibody ${ }^{\dagger}$
}

\author{
Cornelis P. J. Glaudemans, ${ }^{*, \ddagger}$ Laura Lerner,, ,\| G. Doyle Daves, Jr., ${ }^{\ddagger} \perp$ Pavol Kovăč, ${ }^{\ddagger}$ Richard Venable, \# and \\ Ad Bax ${ }^{\S}$ \\ Laboratory of Chemistry and Laboratory of Chemical Physics, National Institute of Diabetes and Digestive and Kidney \\ Diseases, National Institutes of Health, Bethesda, Maryland 20892, and Center for Biologics Evaluation and Research, Food \\ and Drug Administration, Bethesda, Maryland 20892
}

Received June 27, 1990

\begin{abstract}
Transferred nuclear Overhauser enhancement spectroscopy (TRNOE) was used to observe changes in a ligand's conformation upon binding to its specific antibody. The ligands studied were methyl $O-\beta$-D-galactopyranosyl $(1 \rightarrow 6)$-4-deoxy-4-fluoro- $\beta$-D-galactopyranoside $\left(\mathrm{me}^{\mathrm{F}} \mathrm{FGal}_{2}\right)$ and its selectively deuteriated analogue, methyl $O$ - $\beta$-D-galactopyranosyl $(1 \rightarrow 6)$-4-deoxy-2-deuterio-4-fluoro- $\beta$-D-galactopyranoside $\left(\mathrm{me} 4 \mathrm{~F} 2 \mathrm{dGal}_{2}\right.$ ). The monoclonal antibody was mouse IgA X24. The solution conformation of the free ligand me $4 \mathrm{~F} 2 \mathrm{dGal}_{2}$ was inferred from measurements of vicinal ${ }^{1} \mathrm{H}-{ }^{1} \mathrm{H}$ coupling constants, long-range ${ }^{1} \mathrm{H}-{ }^{13} \mathrm{C}$ coupling constants, and NOE cross-peak intensities. For free ligand, both galactosyl residues adopt a regular chair conformation, but the NMR spectra are incompatible with a single unique conformation of the glycosidic linkage. Analysis of ${ }^{1} \mathrm{H}^{-1} \mathrm{H}$ and ${ }^{1} \mathrm{H}^{-13} \mathrm{C}$ constants indicates that the major conformer has an extended conformation: $\phi=-120^{\circ} ; \psi=180^{\circ}$; and $\omega=75^{\circ}$. TRNOE measurements on me4FGal and me4F $2 \mathrm{dGal}_{2}$ in the presence of the specific antibody indicate that the pyranose ring pucker of each galactose ring remains unchanged, but rotations about the glycosidic linkage occur upon binding to X24. Computer calculations indicate that there are two sets of torsion angles that satisfy the observed NMR constraints, namely, $\phi=-152 \pm 9^{\circ} ; \psi=-128 \pm 7^{\circ}$; and $\omega=-158 \pm 6^{\circ}$; and a conformer with $\phi=-53$ $\pm 6^{\circ} ; \psi=154 \pm 10^{\circ}$; and $\omega=-173 \pm 6^{\circ}$. Neither conformation is similar to any of the observed conformations of the free disaccharide. Therefore, the X24 antibody significantly alters the conformation of its ligand upon binding. A new method, based on changes in the fluorine longitudinal relaxation rate, is used to measure the ligand-antibody dissociation rate constant. At $55^{\circ} \mathrm{C}$, this rate constant is found to be $100 \mathrm{~s}^{-1}$.
\end{abstract}

$T_{\text {he }}$ he conformational flexibility of antigenic determinants, and the possible selection of one of these conformations as the one to be recognized by its antibody, has been the object of many studies (Vuk-Pavlović et al., 1978; Gettins et al., 1981; Tainer et al., 1984; Amit et al., 1986; Colman et al., 1987; Davies et al., 1988). For oligosaccharide epitopes, theoretical considerations have been advanced for the prediction of solution conformations (Lemieux \& Bock, 1983). Binding data obtained with oligosaccharides and proteins, including antibodies, together with conformational calculations, have been used to arrive at specific binding interactions (Kabat et al., 1981; Hindsgaul et al., 1985). There is no a priori reason to suspect that low-energy conformations of oligosaccharidic epitopes would not be the ones eliciting the antibody response. However, it is also quite possible that the free energy released upon binding of an epitope to an antibody could more than compensate for the energy required to induce changes in the existing solution conformations of the epitope. We here present evidence showing that the latter is the case for the binding of

\footnotetext{
${ }^{\dagger}$ This work was supported by the Intramural AIDS Targeted Antiviral Program of the Office of the Director of the National Institutes of Health and by an Arthritis Foundation postdoctoral fellowship (L.L.)

* Author to whom correspondence should be addressed.

¿aboratory of Chemistry, National Institutes of Health.

'Laboratory of Chemical Physics, National Institutes of Health.

"Present address: Department of Chemistry, University of Wisconsin, Madison, WI 53706.

${ }^{\perp}$ On leave from the Department of Chemistry, Lehigh University, Bethlehem. PA 18015. Present address: School of Science, Rensselaer Polytechnic Institute, Troy, NY 12180.

\# Food and Drug Administration.
}

a disaccharide epitope to a monoclonal immunoglobulin.

When crystals of antibody, antigen, and the bound complex are not available for analysis by $\mathrm{X}$-ray diffraction, spectrophotometric methods such as temperature-jump fluorescence spectroscopy can be used to detect qualitative changes in antibody conformation (Vuk-Pavlović et al., 1978). NMR spectroscopy has also been used to study antibody-antigen complexes. For example, changes in chemical shifts of histidine protons have been monitored to determine which histidine residues were perturbed upon binding of hapten (Gettins et al., 1981).

Complete and detailed determination by NMR of the conformation of an intact antibody, with its bound antigen, is not feasible because of the large size of such a complex. However, for weakly binding ligands, a simpler NMR approach, developed primarily by Clore and Gronenborn (1982, 1983), is available to study the conformation of the ligand in its bound form. This approach, usually referred to as transferred nuclear Overhauser enhancement (TRNOE) spectroscopy (Balaram et al., 1973; Albrand et al., 1979; Clore \& Gronenborn, 1982, 1983; Levy et al., 1983; Glasel \& Borer, 1986; Andersen et al., 1987), relies on the measurement of magnetization transfer between protons that are close in space $(<\sim 5 \AA)$. For such protons on a small, unbound ligand (MW $<\sim 2000$ ) that is tumbling rapidly in solution, the rate of magnetization transfer is very slow and of opposite sign compared to the very fast transfer that occurs for protons on a ligand that is slowly tumbling because it is bound to a very large molecule, such as an antibody. In either case, the magnetization transfer rate is also proportional to $r^{-6}$, where $r$ is the interproton distance. Provided the ligand is bound to 


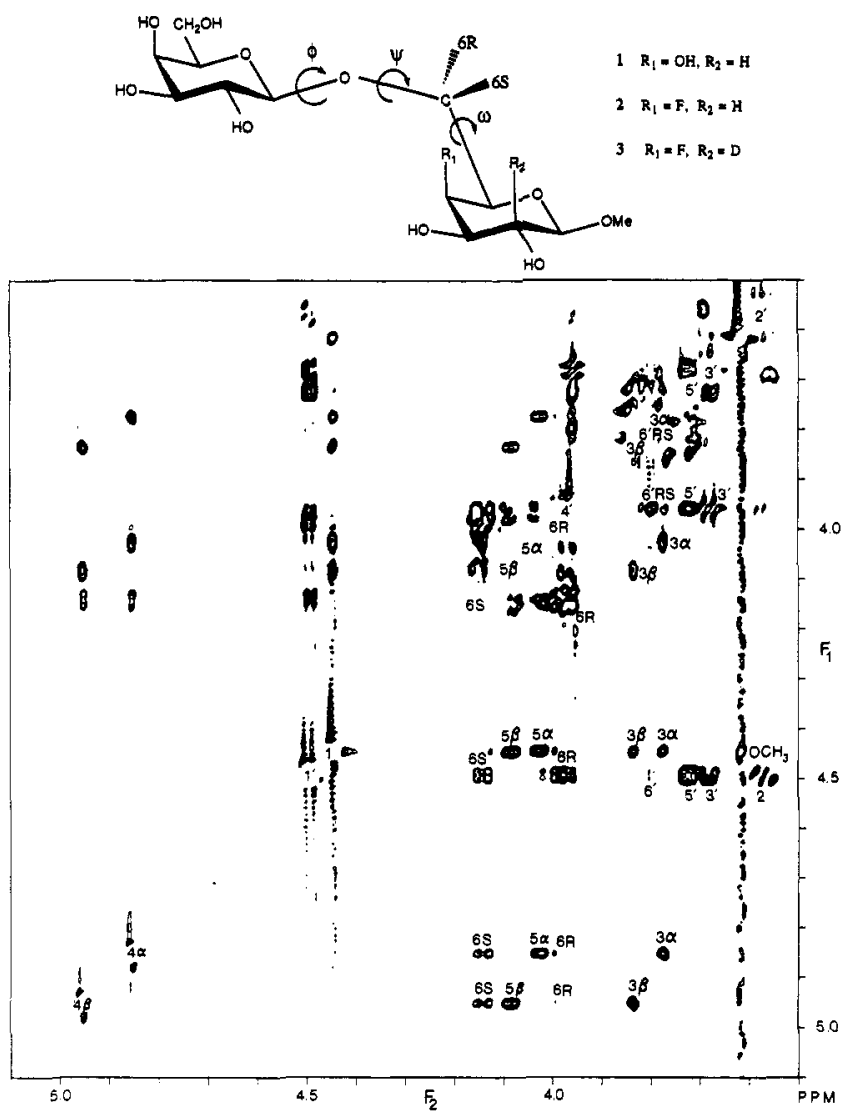

FIGURE 1: NOESY spectrum of free me4F2dGal ${ }_{2}$ (deuteriated in the $\mathrm{C} 2$ position). The spectrum was recorded at $500-\mathrm{MHz}{ }^{1} \mathrm{H}$ frequency, $35^{\circ} \mathrm{C}$, with an average mixing time duration of $303 \mathrm{~ms}$. Further experimental details are given under Materials and Methods.

the antibody for a sufficiently short time, one can exploit this rapid exchange to observe the effect of the bound NOEs (reflecting the bound ligand interproton distances) by observing the intense and narrow signals of excess free ligand present in the same solution. This is the approach used in our present study in which we have determined that the disaccharide epitope studied binds to a specific monoclonal antibody with a conformation that is significantly different from any of the conformations observable by ${ }^{1} \mathrm{H}$ NMR for the free, unbound disaccharide in solution. The major solution conformation found here for the free disaccharide is close to that expected for the corresponding $\beta-(1 \rightarrow 6)$-linked tetraose (the full antigenic determinant; see below) as computed by hard-sphere exo-anomeric (HSEA) calculations (Lemieux \& Bock, 1983; Glaudemans \& Kovä̌̌, 1988).

The antibody used was IgA X24. This monoclonal immunoglobulin (Glaudemans et al., 1973), by amino acid sequence and subsite-binding patterns (Glaudemans, 1987), defines the antigalactan X24 gene family (Hartman \& Rudikoff, 1982; Ollo et al., 1981) to which belong the hybridoma antibodies raised (Pawlita et al., 1982) against gum Ghatti, a predominantly $\beta$ - $(1 \rightarrow 6)$-linked D-galactan (Aspinall et al., 1958). The $\mathrm{X} 24$ antibody is known to maximally bind four successive $\beta-(1 \rightarrow 6)$-linked galactosyl units. However, the disaccharide methyl $O$ - $\beta$-D-galactopyranosyl- $\beta$ - $(1 \rightarrow 6)$-D-galactopyranoside (Kovâč et al., 1984) ( $\mathrm{meGal}_{2}$, structure 1 in Figure 1) is the largest saccharide for which a sufficiently high exchange rate (see below) with free ligand could be obtained and thus offers the best approach to NMR-mediated binding studies with this antibody. Ligand 1 has a free energy of binding with the antibody amounting to $75 \%$ of that which the entire tetrasaccharide epitope has (Glaudemans, 1987). The fluorinated analogue of the disaccharide, methyl $0-\beta$-D-galacto- pyranosyl $(1 \rightarrow 6)$-4-deoxy-4-fluoro- $\beta$-D-galactopyranoside (Kováč \& Glaudemans, 1984) (2, me4FGal ${ }_{2}$ ), was used for this TRNOE study because the fluorine increases the ${ }^{1} \mathrm{H}$ chemical shift dispersion in the fluorinated galactose, allowing a more detailed analysis of the two-dimensional (2D) NOE spectrum. Disaccharide 2 binds IgA X24 with the same affinity and the same ligand-induced tryptophanyl fluorescence characteristics as does the nonfluorinated meGal $_{2}$ (Jolley \& Glaudemans, 1974). For $1, K_{\mathrm{a}}=2.1 \times 10^{4} \mathrm{M}^{-1}$ with a maximum ligand-induced fluorescence change $\left(\Delta F_{\max }\right)$ of $35 \%$, while 2 shows $K_{\mathrm{a}}=2.5 \times 10^{4} \mathrm{M}^{-1}$ and $\Delta F_{\max }=39 \%$. Furthermore, in order to resolve a single but crucial ambiguity in the analysis of the TRNOE spectrum of bound me4FGal, (the chemical shifts of $\mathrm{H} 2$ and $\mathrm{H}^{\prime}$ in the spectrum of 1 nearly coincide), we also studied the spectrum of $\mathrm{me}_{4} \mathrm{Gal}_{2}$ deuteriated selectively at $\mathrm{C} 2\left(3, \mathrm{me} 4 \mathrm{~F} 2 \mathrm{dGal}_{2}\right)$. The synthesis of this disaccharide has been reported elsewhere (Daves et al., 1990).

The conformations of the free disaccharides, me4FGal $_{2}$ and me4F2 $\mathrm{dGal}_{2}$, will be discussed first, followed by an analysis of their conformation in the antibody-bound state. The solution conformations of the free disaccharides 2 and 3 are derived from the ${ }^{1} \mathrm{H}-1 \mathrm{H}$ and ${ }^{1} \mathrm{H}-{ }^{13} \mathrm{C}$ coupling constants (Table I) and their two-dimensional NOE spectra (Figure 1 and Table II).'

\section{Materials AND Methods}

Synthesis of 2 and 3. Me4FGal ${ }_{2}$ was synthesized as described by Kováč et al. (1984). Deuteriation in the C2 position of 2 to obtain 3 is described by Daves et al. (1990).

Preparation and Purification of X24. Ascites fluid, at 0 ${ }^{\circ} \mathrm{C}$, was made $40 \%$ in ammonium sulfate, and the precipitate was collected and dissolved in phosphate-buffered saline (PBS), $\mathrm{pH}$ 7.4. This solution was passed through a column of galactosyl-BSA (Potter \& Glaudemans, 1972), and unbound protein was removed by washing with PBS. Bound IgA was then eluted with $0.2 \mathrm{M}$ predialyzed methyl $\beta$-D-galactopyranoside in PBS. Ligand was removed from the eluate by extensive dialysis against PBS. Polyacrylamide gel electrophoresis in SDS did not reveal evidence for any but the monomeric form of the IgA in the preparation used.

NMR Spectroscopy. PBS in ${ }^{2} \mathrm{H}_{2} \mathrm{O}\left(\mathrm{PBS}-{ }^{2} \mathrm{H}_{2} \mathrm{O}\right)$ was prepared by lyophilization of PBS and repeated dissolution (in ${ }^{2} \mathrm{H}_{2} \mathrm{O}$ ) and relyophilization. The sample of free me4F2 $\mathrm{dGal}_{2}$ in $\mathrm{PBS}-{ }^{2} \mathrm{H}_{2} \mathrm{O}$ was prepared in the same way. The sample containing antibody plus ligand was prepared by repeated dialysis of $7 \mathrm{mg}$ of X24 against $\mathrm{PBS}-{ }^{2} \mathrm{H}_{2} \mathrm{O}$ to yield $1 \mathrm{~mL}$ of a $46 \mu \mathrm{M}$ solution, and a $0.45-\mathrm{mL}$ aliquot of this solution was then added to $0.05 \mathrm{~mL}$ of a solution containing $15 \mathrm{mg} / \mathrm{mL}$ me4F2dGal 2 , yielding concentrations of $4.2 \mathrm{mM}$ ligand and $42 \mu \mathrm{M}$ X24. Spectra of the free digalactoside were collected at $35^{\circ} \mathrm{C}$; TRNOE spectra were collected at $55^{\circ} \mathrm{C}$, the highest temperature at which the antibody does not precipitate after a 24-h experiment. Spectra were obtained at $500 \mathrm{MHz}$ (free ligand) and $600 \mathrm{MHz}$ (antibody plus ligand) on Bruker AM500 and AM600 spectrometers. Scalar coupling constants for free me $4 \mathrm{FGal}_{2}$ were obtained from first-order analysis of the $600-\mathrm{MHz}$ one-dimensional spectrum. Assignments were in agreement with those published previously (Wong et al., 1984). Long-range ${ }^{1} \mathrm{H}^{-13} \mathrm{C}$ connectivities were established by using the reverse-detected HMBC experiment (Bax \& Summers, 1986). The relative intensities in this spectrum were used for a qualitative estimate of the $J_{\mathrm{CH}}$ couplings. The $J$ coupling between $\mathrm{H}^{\prime}$ and $\mathrm{C} 6$ was measured by the selective proton-flip method (Bax \& Freeman, 1982). The NOESY

${ }^{1}$ No conformational differences were observed $\left(600-\mathrm{MHz}{ }^{1} \mathrm{H}\right.$ spectra) between $\mathrm{meGal}_{2}$ (1) and the corresponding $\mathrm{meGal}_{4}$. 
spectrum of the free ligand was recorded with the standard NOESY pulse scheme (Macura \& Ernst, 1980). The results of four different mixing times $(300,301.1,306.2$, and 307.3 $\mathrm{ms}$ ) were coadded to minimize the effect of zero-quantum contributions to cross-peak intensities (Rance et al., 1985a,b). The number of transients recorded per $t_{1}$ value was 32 ( 8 per mixing time). Acquisition times were $410 \mathrm{~ms}\left(t_{2}\right)$ and $160 \mathrm{~ms}$ $\left(t_{1}\right)$. The digital resolution in the final spectrum was $2.5 \mathrm{~Hz}$ in both dimensions. Cosine bell digital filtering was used in both dimensions. The delay time between scans was $3 \mathrm{~s}$. The 2D TRNOE spectrum was recorded by using a modification of the standard NOESY pulse sequence. To reduce the diagonal and cross-peak intensities resulting from the antibody itself, a short delay was inserted prior to the evolution period, during which chemical shift evolution was refocused by the application of a composite $180^{\circ}$ pulse. The pulse sequence used was $90^{\circ}{ }_{\phi 1}-\Delta-180^{\circ}{ }_{\phi 2}-\Delta-t_{1}-90^{\circ}{ }_{x}-\tau-90^{\circ}{ }_{\phi 3}-$ Acq, with phases $\phi_{1}=x,-x ; \phi_{2}=8(x), 8(y) 8(-x), 8(-y) ; \phi_{3}=2(x)$, $2(y), 2(-x), 2(-y) ;$ Acq $=x,-x, y,-y, 2(-x, x,-y, y), x,-x$, $y,-y$.

Positive and negative frequencies were distinguished by using time-proportional phase incrementation (TPPI) of the phases $\phi_{1}$ and $\phi_{2}$ (Marion \& Wüthrich, 1983). The delay, $\Delta$, was set to $2 \mathrm{~ms}$, and the results of four mixing periods, $\tau=150$, $151,155.2$, and $156.2 \mathrm{~ms}$, were coadded. Thirty-two scans were acquired per $t_{1}$ value. Acquisition times were $147 \mathrm{~ms}$ $\left(t_{2}\right)$ and $100 \mathrm{~ms}\left(t_{1}\right)$, and the delay between scans was $2.5 \mathrm{~s}$. The digital resolution in the final $2 \mathrm{D}$ spectrum is $7 \mathrm{~Hz}\left(F_{2}\right)$ and $5 \mathrm{~Hz}\left(F_{1}\right)$. Apodization with a $60^{\circ}$ shifted sine bell was used in both dimensions.

Molecular Modeling. To determine which possible conformations were compatible with the observed NOE data, restrained molecular dynamics calculations were performed, by using the program CHARMM (Brooks et al., 1983). Because the location of the antibody atoms were not known, these simulations were conducted for the ligand only, in a vacuum. Simulations with different initial starting values for the interglycosidic angles, $\phi, \psi$, and $\omega$, were conducted starting with rapid heating to high temperature $(1000 \mathrm{~K})$ and low NMR force constants $\left(\sim 21 \mathrm{~kJ} / \AA^{2}\right)$. The initial starting values represented all $27\left(3^{3}\right)$ torsional minima. During the course of each 80-ps simulation, the force constants were increased to $167 \mathrm{~kJ} / \AA^{2}$ and the temperature was decreased to $300 \mathrm{~K}$. As a last step, each of the final structures was subjected to energy minimization in the presence of the NMR constraints. These computer calculations indicate that there are two different glycosidic linkage conformations that both satisfy the NMR constraints. One set of conformations is centered about dihedral angles of $\phi=-152 \pm 9^{\circ} ; \psi=-128 \pm 7^{\circ}$; and $\omega=$ $-158 \pm 6^{\circ}$. The second set of structures has glycosidic linkage angles of $\phi=-53 \pm 6^{\circ} ; \psi=154 \pm 10^{\circ}$; and $\omega=-173 \pm 6^{\circ}$. The energy calculated for each of these structures is about 10 $\mathrm{kJ}$ higher than the energy obtained if the same simulations are performed without any NMR constraints. Distinguishing between the two sets of conformations would require a more quantitative measurement of the $\mathrm{Hl}^{\prime}-\mathrm{H} 6 \mathrm{R} / \mathrm{H} 6 \mathrm{~S}$ NOE interactions, which is not possible because of spin diffusion allowed by the low ligand off-rate, $k_{\text {off }}$.

\section{RESULTS}

Conformation of the Free Ligand. The solution conformation of the free disaccharide can be obtained by analysis of ${ }^{1} \mathrm{H}-{ }^{1} \mathrm{H}$ coupling constants, ${ }^{1} \mathrm{H}-{ }^{13} \mathrm{C}$ couplings, and cross-peak intensities in the 2D NOE spectrum. A comparison of $J$ coupling constants indicates no significant difference in the conformations of $\mathrm{meGal}_{2}, \mathrm{me}_{4} \mathrm{FGal}$, and me4F2dGal ${ }_{2}$ (Table

\begin{tabular}{|c|c|c|c|}
\hline interacting nuclei & $J(\mathrm{~Hz})$ & interacting nuclei & $J(\mathrm{~Hz})$ \\
\hline $\mathrm{H} 1, \mathrm{H} 2$ & 7.9 & $\mathrm{H} 1^{\prime}, \mathrm{H} 2^{\prime}$ & 7.9 \\
\hline $\mathrm{H} 2, \mathrm{H} 3$ & 9.9 & $\mathrm{H} 2^{\prime}, \mathrm{H}^{\prime}$ & 9.9 \\
\hline $\mathrm{H} 3, \mathrm{H} 4$ & 2.8 & $\mathrm{H}^{\prime}, \mathrm{H}^{\prime}$ & 3.5 \\
\hline $\mathrm{H} 4, \mathrm{H} 5$ & $<1(1.0)^{a}$ & $\mathrm{H} 4^{\prime}, \mathrm{H} 5^{\prime}$ & 1.0 \\
\hline $\mathrm{H} 5, \mathrm{H} 6 \mathrm{~S}$ & $4.6(4.0)$ & $\mathrm{H} 5^{\prime}, \mathrm{H} 6^{\prime} S$ & 4.5 \\
\hline $\mathrm{H} 5, \mathrm{H} 6 R$ & $7.6(7.7)$ & $\mathrm{H} 5^{\prime}, \mathrm{H} 6^{\prime} R$ & 7.6 \\
\hline $\mathrm{H} 6 S, \mathrm{H} 6 R$ & $11.2(10.8)$ & $\mathrm{H} 6^{\prime} S, \mathrm{H} 6^{\prime} R$ & 11.7 \\
\hline $\mathrm{F} 4, \mathrm{H} 3$ & 29 & $\mathrm{~F} 4, \mathrm{H} 4$ & 50.0 \\
\hline $\mathrm{F} 4, \mathrm{H} 5$ & 29.6 & $\mathrm{H} 1^{\prime}, \mathrm{C} 6$ & 4.8 \\
\hline $\mathrm{H} 6 S, \mathrm{C} 4$ & small $^{b}$ & $\mathrm{H} 6 R, \mathrm{C} 4$ & small $^{b}$ \\
\hline $\mathrm{H} 6 S, \mathrm{Cl}^{\prime}$ & medium $^{b}$ & $\mathrm{H} 6 R, \mathrm{Cl}^{\prime}$ & medium $^{b}$ \\
\hline $\mathrm{Hl}^{\prime}, \mathrm{C} 6$ & 4.8 & & \\
\hline
\end{tabular}

${ }^{a}$ Values in parentheses refer to the nonfluorinated disaccharide. ${ }^{b}$ Qualitative estimate of the size of the ${ }^{1} \mathrm{H}^{-13} \mathrm{C}$ coupling constant obtained from an HMBC experiment. Small is $<2.5 \mathrm{~Hz}$; medium is $2<$ $J<4 \mathrm{~Hz}$

I). For the case of rapidly interconverting conformers, the $J$ couplings represent the time-weighted averages of the $J$ couplings of the individual conformers. However, the observed NOE cross-peak intensities correspond to the time-weighted average of $r^{-6}$, where $r$ is the interproton distance; i.e., a conformation that yields a very short interproton distance for one of its conformers can give significant NOE cross-peak intensities even if this conformer is only present for a relatively small fraction of time. The $J$ couplings are summarized in Table I. The proton and carbon atoms on the ring bearing the methyl aglycon are labeled 1-6, and those on the other ring are labeled $1^{\prime}-6^{\prime}$. The values of $J_{1,2}$ and $J_{1^{\prime}, 2^{\prime}}$ verify that the two galactose residues possess the $\beta$ configuration at $\mathrm{Cl}$. The values of $J_{2,3}, J_{2^{\prime}, 3^{\prime}}$, and $J_{3^{\prime}, 4^{\prime}}$ are consistent with both rings being in the ${ }^{4} C_{1}$ conformation. This is confirmed by intense NOEs between protons 1,3 , and 5 , and between $1^{\prime}, 3^{\prime}$, and $5^{\prime}$ (Figure 1). Analysis of the conformation around the interglycosidic linkage presents a more complicated problem. For a disaccharide linked $1 \rightarrow 6$, three torsion angles, $\phi, \psi$, and $\omega$, can be used to specify the intersaccharide angles (Marchessault \& Perez, 1979). In this paper we use the following definition (Lemieux \& Koto, 1974): looking along the bond of interest, the heaviest atom at the front of the view will be turned to cover the heaviest atom at the rear. If the direction is clockwise, the sign of the angle is positive; if counterclockwise, negative. For determining the glycosidic linkage conformation, stereospecific assignment of the methylene protons in the 6-position is essential. For $\mathrm{meGal}_{2}(\mathbf{1})$, the most downfield $\mathrm{H} 6$ proton was proven to be $6 S$ (Ohrui et al., 1985). Comparison of $J$ couplings and chemical shifts of the fluorinated and nonfluorinated disaccharides strongly suggests the same to be true for 2 and 3 .

The couplings $J(5,6 S)(4.0 \mathrm{~Hz})$ and $J(5,6 R)(7.6 \mathrm{~Hz})$ are incompatible with a single dihedral angle if analyzed by using a Karplus equation parametrized by Altona and Haasnoot (1980). If one assumes that the observed NMR couplings result from the time average of only the three standard rotamers, $-60^{\circ},+60^{\circ}$, and $180^{\circ}$ (Brisson \& Carver, 1983), one calculates populations for these rotamers of $21 \%, 66 \%$, and $13 \%$, respectively. However, the very weak NOE between $\mathrm{H} 4$ and $\mathrm{H} 6 R$ is incompatible with a $21 \%$ population of the $-60^{\circ}$ rotamer. Both $J$ couplings and NOEs are compatible with a two-state model with $\omega=75^{\circ}$ and $180^{\circ}$, with occupation levels of $75 \%$ and $25 \%$, respectively, although the presence of more conformers cannot be excluded. Less information is available for defining the $\phi$ and $\psi$ angles. The coupling between $\mathrm{Hl}^{\prime}$ and $\mathrm{C} 6$ is $4.2 \mathrm{~Hz}$; both $\mathrm{H} 6 \mathrm{~S}$ and $\mathrm{H} 6 R$ show medium-sized $J$ couplings $(2.5<J<4.5 \mathrm{~Hz})$ with $\mathrm{C1}^{\prime}$, as judged by the relative intensities of the $\mathrm{H} 6 S$ and $\mathrm{H} 6 R$ correlations to $\mathrm{Cl}^{\prime}$ 
in an HMBC spectrum (data not shown). $\mathrm{H}^{\prime}$ ' shows strong NOE interactions with both $\mathrm{H} 6 \mathrm{~S}$ and $\mathrm{H} 6 R$. These NOEs and the $J\left(\mathrm{H}^{\prime}, \mathrm{C} 6\right)$ coupling are compatible with $\phi=120^{\circ}$ and $\psi$ $=180^{\circ}$. However, this conformation is incompatible with the medium-sized $J\left(\mathrm{H} 6 S, \mathrm{C}^{\prime}\right)$ and $J\left(\mathrm{H} 6 R, \mathrm{C} 1^{\prime}\right)$ couplings. Moreover, a weak NOE is observed between $\mathrm{H}^{\prime}{ }^{\prime}$ and $\mathrm{H} 5$. No single conformation exists that satisfies the distance constraints imposed by the $(\mathrm{H} 1, \mathrm{H} 6 \mathrm{~S} / \mathrm{H} 6 \mathrm{R})$ and $(\mathrm{H} 1, \mathrm{H} 5)$ NOEs, and it is likely that the $\psi$ angle exists as a time average of conformers with $\psi=+60^{\circ},-60^{\circ}$, and $180^{\circ}$. Insufficient NMR data are available to make a quantitative estimate of the population levels of these conformers. However, the relatively strong $\left(\mathrm{H}^{\prime}, \mathrm{H} 6 S\right)$ and $\left(\mathrm{H}^{\prime}, \mathrm{H} 6 \mathrm{R}\right)$ NOEs suggest that the extended conformation with $\phi=-120 \pm 60^{\circ}$ and $\psi=180^{\circ}$ is significantly populated. To satisfy the $\left(\mathrm{H} 1^{\prime}, \mathrm{H} 5\right)$ NOE constraint, population of the $\psi=+60^{\circ}$ or of the $\psi=-60^{\circ}$ rotamer is also required.

Conformation of the Bound Ligand. It is not possible to obtain $J$ coupling information for the bound ligand, and therefore, the TRNOE spectrum provides the only source of experimental structural information. The TRNOE experiment requires a relatively rapid exchange of bound and free ligand:

$$
\text { free ligand } \underset{k_{\text {off }}}{\stackrel{k_{\text {on }}}{\rightleftarrows}} \text { bound ligand }
$$

where $k_{\text {on }} / k_{\text {off }}=K_{\mathrm{a}}$, the binding constant.

For the TRNOE experiment it is not the binding constant, $K_{\mathrm{a}}$, that determines the feasibility of the experiment, but rather the dissociation rate constant, $k_{\text {off }}$. If the dissociation rate constant is too low, spin diffusion occurs for the bound ligand, even if it binds the antibody only once during the mixing time of the 2D NOE experiment. Note, that, in this case, even in the presence of a large excess of free ligand, the observed TRNOE effect builds up linearly with mixing time because the number of ligands that have been bound increases linearly with time. Therefore, unlike regular NOE studies, a linear buildup of cross-peak intensity as a function of mixing time does not prove the absence of spin diffusion. For an antibody $\left(M_{\mathrm{r}}=150000\right)$ a correlation time of about $60-100 \mathrm{~ns}$ is expected. For this molecular tumbling rate, it can be calculated that undesirable indirect NOE effects may become observable if $k_{\text {off }}<\sim 200 \mathrm{~s}^{-1}$. At $55^{\circ} \mathrm{C}$, the highest temperature at which the antibody remains stable for at least $24 \mathrm{~h}$, we measured $k_{\text {off }}=90 \pm 15 \mathrm{~s}^{-1}$ (see below). Thus, under these conditions, some indirect NOE effects are expected and an exact quantitative interpretation becomes impossible. In principle, one might hope that a complete relaxation matrix treatment (Keepers \& James, 1984) could be used to account for the indirect NOE effects. However, because the position of the antibody protons is unknown, this approach is not feasible in the present case.

Figure 2 shows the 2D TRNOE spectrum, recorded at $600-\mathrm{MHz}{ }^{1} \mathrm{H}$ frequency, with a 100 -fold molar excess of ligand (50-fold excess per binding site). Comparison with the 2D NOE spectrum of the free ligand shows a number of similarities; most importantly, intense NOEs are observed between protons 1,3 , and 5 , and between protons $1^{\prime}, 3^{\prime}$ and $5^{\prime}$ (Figure 2 ), indicating that the rings have remained in the ${ }^{4} C_{1}$ conformation. Weak NOE cross-peaks are observed between $\mathrm{H} 1$ and $\mathrm{H} 4$, which must arise from indirect transfer via $\mathrm{H} 3$ and H5. Note that both $\mathrm{H} 3$ and $\mathrm{H} 5$ provide efficient relay of NOE intensity because of the short $\mathrm{H} 1 / \mathrm{H} 3, \mathrm{H} 5$ and $\mathrm{H} 4 / \mathrm{H} 3, \mathrm{H} 5$ distances. The fact that the $\mathrm{H} 1, \mathrm{H} 4 \mathrm{NOE}$ cross-peak is much weaker than the direct $\mathrm{H} 1 / \mathrm{H} 3, \mathrm{H} 5$ and $\mathrm{H} 3, \mathrm{H} 5 / \mathrm{H} 4$ NOEs indicates that spin diffusion is not extensive. In the same manner, indirect NOE transfer is seen between $\mathrm{H} 1$ and $\mathrm{H} 6 R$

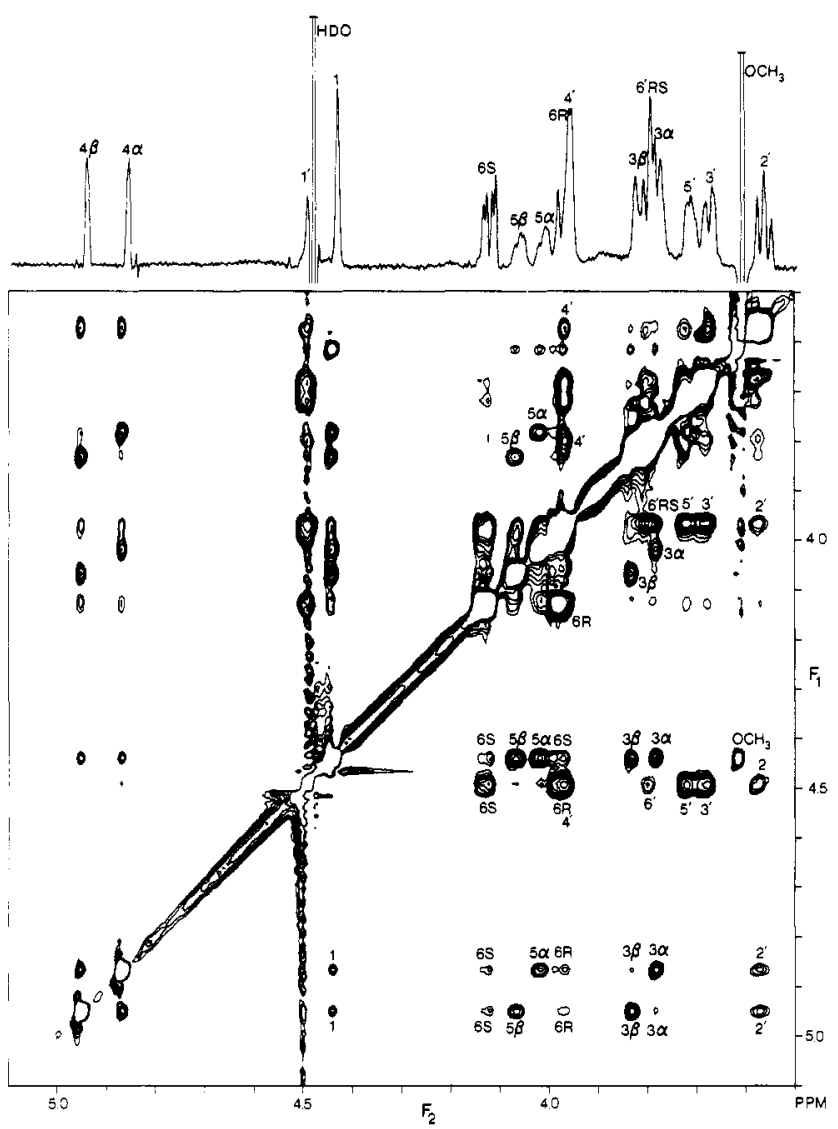

FIGURE 2: 2D TRNOE spectrum of me4F2 $\mathrm{dGal}_{2}$ (deuteriated in the $\mathrm{C} 2$ position), in the presence of IgA X24. The ligand:Fab binding site ratio is $50: 1$. The spectrum was recorded at $600-\mathrm{MHz}{ }^{1} \mathrm{H}$ frequency, $55^{\circ} \mathrm{C}$, with an average mixing time duration of $153 \mathrm{~ms}$. Further experimental details are given under Materials and Methods.

Table II: Selected Peak Volumes in the NOE and TRNOE Spectra of me4F2DGal ${ }^{a}$

\begin{tabular}{|c|c|c|c|c|c|}
\hline proton pair & $\mathrm{NOE}^{b}$ & TRNOE $^{c}$ & proton pair & $\mathrm{NOE}^{b}$ & TRNOE $^{c}$ \\
\hline $\mathrm{H} 1, \mathrm{H}^{\prime}$ & 1000 & 1000 & $\mathrm{H} 4, \mathrm{H} 6 \mathrm{R}$ & -2.5 & 28 \\
\hline $\mathrm{H} 1, \mathrm{OCH}_{3}$ & -15 & 79 & $\mathrm{H} 4, \mathrm{H}^{\prime}{ }^{\prime}$ & 0 & 35 \\
\hline $\mathrm{H} 1, \mathrm{H}^{3}$ & -18 & 57 & $\mathrm{H} 5, \mathrm{HI}^{\prime}$ & -4 & 10 \\
\hline $\mathrm{Hl}, \mathrm{H} 4$ & 0 & 12 & $\mathrm{H} 6 S, \mathrm{H} 6 R$ & -81 & 194 \\
\hline $\mathrm{Hl}, \mathrm{HS}$ & -27 & 91 & $\mathrm{H} 6 \mathrm{~S}, \mathrm{Hl}^{\prime}$ & -11 & 55 \\
\hline $\mathrm{H} 1, \mathrm{H} 6 \mathrm{~S}$ & -1 & 16 & $\mathrm{H} 6 R, \mathrm{H} 1^{\prime}$ & -20 & $85^{d}$ \\
\hline $\mathrm{H} 1, \mathrm{H} 6 R$ & -1.7 & 28 & $\mathrm{H} 1^{\prime}, \mathrm{H} 2^{\prime}$ & -5 & 24 \\
\hline $\mathrm{H} 3, \mathrm{H} 4$ & -23 & 79 & $\mathrm{H}^{\prime}, \mathrm{H}^{\prime}$ & -18 & $65^{\circ}$ \\
\hline $\mathrm{H} 3, \mathrm{H} 5$ & -19 & 53 & $\mathrm{H} 1^{\prime}, \mathrm{H}^{\prime}$ & -31 & $65^{e}$ \\
\hline $\mathrm{H} 4, \mathrm{H} 5$ & -18 & 47 & $\mathrm{H}^{\prime}, \mathrm{H}^{\prime}$ & -2 & 20 \\
\hline $\mathrm{H} 4, \mathrm{H} 6 \mathrm{~S}$ & -13 & 24 & $\mathrm{H} 4^{\prime}, \mathrm{H} 6^{\prime} R S$ & -14 & 65 \\
\hline
\end{tabular}

${ }^{a}$ Peak volumes for me4FGal 2 were similar (data not shown). ${ }^{b}$ Recorded at $500 \mathrm{MHz}, 37^{\circ} \mathrm{C}$, average mixing time of $303 \mathrm{~ms}$. c Recorded at $600 \mathrm{MHz}, 55^{\circ} \mathrm{C}$, average mixing time of $153 \mathrm{~ms}$. ${ }^{d}$ This cross-peak partially overlaps the $\mathrm{H}^{\prime}, \mathrm{H} 4^{\prime}$ cross-peak. The reported integral has been reduced by the intensity found for the $\mathrm{H} 1, \mathrm{H} 4$ crosspeak. ' In the TRNOE spectrum, the $\mathrm{H}^{\prime}{ }^{\prime}, \mathrm{H}^{\prime}$ ' and $\mathrm{H}^{\prime}, \mathrm{H}^{\prime}{ }^{\prime}$ crosspeaks could not be integrated separately because of overlap. The reported value of 65 is half the total integral for both cross-peaks.

(via $\mathrm{H} 5$ ) and between $\mathrm{H} 1$ and $\mathrm{H} 6 S$ (via $\mathrm{H} 5$ and $\mathrm{H} 6 R$ ). The most striking new feature in the TRNOE spectrum of Figure 2 is the presence of an interresidue NOE between $\mathrm{H} 4$ and $\mathrm{H}^{\prime}$. This NOE is about $50 \%$ stronger than the $\mathrm{H} 1^{\prime}, \mathrm{H} 2^{\prime}$ NOE (interproton distance $3.04 \AA$ ), suggesting a distance between $\mathrm{H} 4$ and $\mathrm{H} 2^{\prime}$ shorter than $3 \AA$. It is important to note that, even at contour levels much lower than shown in the spectrum of Figure 1, no trace of an NOE interaction between $\mathrm{H}^{\prime}$ and H4 can be observed for either of the free disaccharides 2 or 3. Other interesting features are that the H4,H6S and $\mathrm{H} 4, \mathrm{H} 6 R$ NOEs are both rather weak and that $\mathrm{Hl}^{\prime}, \mathrm{H} 6 \mathrm{R}$ is 

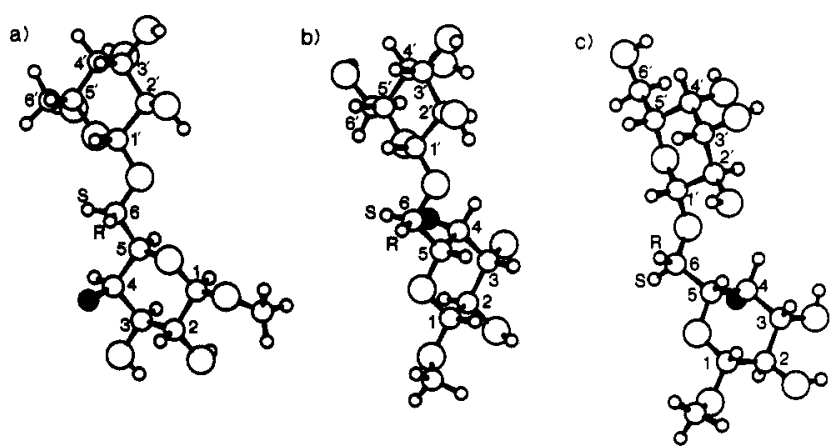

FIGURE 3: Comparison of the most populated conformer in free solution (a) and the possible antibody-bound conformations (b,c) of $\mathrm{Me}_{\mathrm{FGal}}$. The conformers have torsion angles $\phi, \psi$, and $\omega$ of (a) $-120^{\circ}, 180^{\circ}$, and $75^{\circ} ;$ (b) $-53^{\circ}, 154^{\circ}$, and $-173^{\circ}$; and (c) $-152^{\circ}$, $-128^{\circ}$, and $-158^{\circ}$. Fluorime is indicated in black.

significantly stronger than $\mathrm{H} 1, \mathrm{H} 6 \mathrm{~S}$. A comparison of integrated peak intensities for the TRNOE spectrum and the 2D NOE spectrum of the free ligand is given in Table II. Even though the NOE intensities cannot be interpreted in a rigorous quantitative manner, the NOEs involving the $\mathrm{H} 6$ protons, and in particular the $\mathrm{H} 4 / \mathrm{H} 2^{\prime} \mathrm{NOE}$, strongly constrain the possible interglycosidic linkage conformations. Both manual model building and restrained molecular dynamics, followed by every minimization using the program CHARMM (Brooks et al., 1983) on a computer model containing the above NOE constraints, suggest that the observed data are compatible with two distinctly different conformations in the bound form. One set of conformations centers around interglycosidic torsion angles of $\phi=-152 \pm 9^{\circ}, \psi=-128 \pm 7^{\circ}$, and $\omega=-158 \pm 6^{\circ}$. A second set of conformations centers around $\phi=-53 \pm 6^{\circ}, \psi$ $=154 \pm 10^{\circ}$, and $\omega=-173 \pm 6^{\circ}$. The first set of conformations is preferred over the second set because, for the first set, the $\mathrm{H} 1^{\prime}-\mathrm{H} 6 R / \mathrm{H} 6 S$ NOEs agree more closely with the interproton distances. However, because the accuracy of distance determination is relatively low due to proton spin diffusion, the second set of conformations cannot be ruled out. The difference in energy between the major free conformation and either of the two bound forms is about $2 \mathrm{kcal} / \mathrm{mol}$. The major free conformation and the two possible antibody-bound conformations are compared in Figure 3.

Measurement of the Dissociation Rate Constant. The presence of the fluorine nucleus in the ligand provides a convenient means for measuring the ligand-antibody dissociation rate, $k_{\text {off }}$. The $\mathrm{H} 4$ resonance is split into two $\mathrm{H}-\mathrm{F}$ doublet components that are separated by $50 \mathrm{~Hz}$ and are labeled $\mathrm{H} 4 \alpha$ and $\mathrm{H} 4 \beta$, where $\alpha$ and $\beta$ indicate the fluorine spin state. Exchange-type cross-peaks between these two heteronuclear doublet components are present (parallel to the diagonal and therefore invisible in Figure 1) because of $T_{1}$ relaxation of the fluorine nucleus. These cross-peaks in the spectrum of Figure 1 have an intensity of $3.9 \%$ for the average mixing time duration of $303 \mathrm{~ms}$, indicating a fluorine transition probability, $\boldsymbol{W}_{\mathrm{f}},=0.129 \mathrm{~s}^{-1}$. In the TRNOE spectrum (Figure 2) this off-diagonal cross-peak intensity corresponds to the weighted average, $W_{\mathrm{a}}$, of the transition probabilities, $W_{\mathrm{f}}$ and $W_{\mathrm{b}}$, of the free and bound ligands. Because the ligand:binding site excess is 50 -fold

$$
W_{\mathrm{a}}=0.98 W_{\mathrm{f}}+0.02 W_{\mathrm{b}}
$$

The measured $W_{\mathrm{a}}$ equals $0.30 \mathrm{~s}^{-1}$, and therefore, $W_{\mathrm{b}}=8.7 \mathrm{~s}^{-1}$.

For the $\mathrm{H} 4, \mathrm{H} 3$ cross-peaks (Figure 2), two weak additional cross-peaks, $(\mathrm{H} 4 \alpha, \mathrm{H} 3 \beta)$ and $(\mathrm{H} 4 \beta, \mathrm{H} 3 \alpha)$, are observed. These correspond to molecules that have been bound during the mixing period and for which the fluorine has changed its spin state from $\alpha$ to $\beta$, or vice versa. The fluorine transition probability for ligands that have been bound during the mixing period is given by

$$
W_{\mathrm{m}}=(1-\tau / T) W_{\mathrm{f}}+(\tau / T) W_{\mathrm{b}}
$$

where $\tau$ is the total average lifetime in the bound state (including multiple binding events) and $T$ is the duration of the mixing time in the TRNOE experiment $(153 \mathrm{~ms})$. The cross-peak intensity ratio $(\mathrm{H} 4 \alpha, \mathrm{H} 3 \beta) /(\mathrm{H} 4 \alpha, \mathrm{H} 3 \alpha)$ equals 0.12 , yielding $W_{\mathrm{m}}=0.74 \mathrm{~s}^{-1}$. Using expression 2, one finds $\tau=11$ ms. After correcting for multiple binding events, one obtains $k_{\text {off }} \approx 105 \mathrm{~s}^{-1}$. Upon reducing the temperature, the exchange rate rapidly decreases. At $25^{\circ} \mathrm{C}$, no negative NOEs between sugar protons were present and a few weak positive NOEs were observed, indicating that the NOEs for the free ligand dominated the TRNOE effect. This is expected to occur for $k_{\text {off }}$ $<\sim 30 \mathrm{~s}^{-1}$; during the long bound time, the sugar loses all its longitudinal magnetization (needed for the TRNOE) because of spin diffusion with the antibody protons.

\section{CONCLUSIONS}

The results obtained indicate a distinct change, upon binding to the antibody, in the torsion angles of the interglycosidic linkage of the ligand. The most compelling evidence for this change is the presence of a relatively intense NOE between the $\mathrm{H} 4$ proton of the first methyl $\beta$-D-galactoside ring and the $\mathrm{H} 2^{\prime}$ proton of the D-galactosyl group. In our initial binding studies, the nondeuteriated, fluorinated disaccharide 2 was used. Because the chemical shifts of $\mathrm{H} 2$ and $\mathrm{H}^{2}$ are nearly coincident, it was not possible to unambiguously distinguish between $\mathrm{H} 4, \mathrm{H} 2^{\prime}$ cross-peaks and $\mathrm{H} 4, \mathrm{H} 2$ cross-peaks (which would arise from spin diffusion). Deuteriation at the $\mathrm{C} 2$ position resolved this ambiguity and proved that the observed cross-peaks stem from the $\mathrm{H} 4, \mathrm{H} 2$ ' interaction. In the NOESY spectrum of the free disaccharide no such cross-peak can be observed, even at extremely low contour levels, suggesting that the bound conformation is not one of the conformers of the free disaccharide. The calculated energy for the bound conformation is significantly higher then that for the extended conformations; this increase in energy most likely is compensated for by favorable binding interactions between the sugar and the antibody.

Transferred NOE studies have shown conformational changes in a number of ligands upon binding to their receptors. Most recently, work by Anglister et al. $(1989,1990)$ indicates that short peptide fragments of cholera toxin, which are unstructured in free solution, possess a distinct conformation when bound to Fab fragments, although the exact bound conformation has not yet been elucidated. Behling et al. (1988) reported changes in the acetylcholine conformation upon binding to its receptor. Clore et al. (1986) reported a single conformation for a tetrapeptide when bound to porcine pancreatic elastase, whereas the peptide is known to exist as a mixture of conformations in free solution. Ferrin and Mildvan (1986) reported unusual conformations for oligoribonucleotides when bound to DNA polymerase I, and Gronenborn and Clore (1982) found that, for binding, the adenosine cyclic $3^{\prime}, 5^{\prime}$-phosphate receptor protein selects the syn conformation from a syn/anti equilibrium mixture of the free AMP.

The flexibility of an antigen and its putative ability to adapt its conformation to fit a recognition site on an antibody have been a matter of debate. The conformation of antibodies has also been studied as a function of binding to antigens. Recent results from X-ray diffraction studies of crystalline antibody-antigen complexes have provided opposing examples. 
For example, no change was detected in the tertiary structure of lysozyme when it was bound to the Fab fragment of a monoclonal antibody (Amit et al., 1986). However, changes in the antibody hinge region were observed upon binding of whole antibody to its antigen, lysozyme (Davies et al., 1988). Changes in the structure of influenza virus neuraminidase were found when it was bound to an antibody (Colman et al., 1987), and X-ray crystallographic data of this complex were not compatible with an inflexible lock-and-key model. Antibodies directed against highly flexible peptide fragments corresponding to sequences of myohemoerythrin reacted strongly with the native protein, while antibodies prepared against less mobile sequences did not (Tainer et al., 1984). Thus, it appears that antigen flexibility can be important for antigenic specificity.

Although the conformation of the bound ligand cannot be determined unambiguously, careful inspection of the NOESY spectrum of the free disaccharide in the regions where the $\mathrm{H} 4-\mathrm{H} 2^{\prime}$ cross-peaks would appear shows no indication of any such interaction, indicating that the population of the "bound conformer" is unnoticeably low or absent in free solution. Thus, the results presented here show that an antibody binding site can act as a template to induce a conformational change of the ligand in order to bind it.

Registry No. 1, 77790-33-1; 2, 92397-31-4; 3, 129707-58-0.

\section{REFERENCES}

Albrand, J. P., Birdsall, B., Feeney, J., Roberts, G. K. C., \& Burgen, A. S. V. (1979) Int. J. Biol. Macromol. 1, 37-49. Altona, C., \& Haasnoot, C. A. G. (1980) Org. Magn. Reson. 13, 417-425.

Amit, A. G., Mariuzza, R. A., Phillips, S. E. V., \& Poljak, R. J. (1986) Science 233, 747-753.

Andersen, N. H., Eaton, H. L., \& Nguyen, K. T. (1987) Magn. Reson. Chem. 25, 1025-1034.

Anglister, J., \& Zilber, B. (1990) Biochemistry 29, 921-928.

Anglister, J., Levy, R., \& Sherf, T. (1989) Biochemistry 28, 3360-3365.

Aspinall, G. O., Auret, B. J., \& Hirst, E. L. (1958) J. Chem. Soc., 4408-4414.

Balaram, P., Bothner-By, A. A., \& Breslow, E. (1973) Biochemistry 12, 4695-4704.

Bax, A., \& Freeman, R. (1982) J. Am. Chem. Soc. 104, 1100-1101.

Bax, A., \& Summers, M. F. (1986) J. Am. Chem. Soc. 108, 2093-2094.

Behling, R. W., Yamane, T., Navon, G., \& Jelinski, L. W. (1988) Proc. Natl. Acad. Sci. U.S.A. 85, 6721-6725.

Brisson, J. R., \& Carver, J. P. (1983) Biochemistry 22, 1362-1368.

Brooks, B. R., Bruccoleri, R. E., Olafson, B. D., States, D. J., Swaminathan, S., \& Karplus, M. (1983) J. Comput. Chem. 4, 187-217.

Clore, G. M., \& Gronenborn, A. M. (1982) J. Magn. Reson. $48,402-417$.

Clore, G. M., \& Gronenborn, A. M. (1983) J. Magn. Reson. 53, 423-448.

Clore, G. M., \& Gronenborn, A. M., Carlson, G., \& Myer, E. F. (1986) J. Mol. Biol. 190, 259-267.

Colman, P. M., Lver, W. G., Varghese, J. N., Baker, A. T., Tulloch, P. A., Air, G. M., \& Webster, R. G. (1987) Nature 326, 358-363.

Daves, G. D., Jr., Kovā̌c, P., \& Glaudemans, C. P. J. (1990) J. Carbohydr. Chem. 9, 101-112.
Davies, D. R., Sheriff, S. \& Padlan, E. A. (1988) J. Biol. Chem. 263, 10541-10544.

Ferrin, L. J., \& Mildvan, A. S. (1986) Biochemistry 25, 5131-5145.

Gettins, P., Boyd, J., Glaudemans, C. P. J., Potter, M., \& Dwek, R. A. (1981) Biochemistry 20, 7463-7469.

Glasel, J. A., \& Borer, P. N. (1986) Biochem. Biophys. Res. Commun. 141 (3), 1267-1273.

Glaudemans, C. P. J. (1987) Mol. Immunol. 24, 371-377.

Glaudemans, C. P. J., \& Kováč, P. (1988) Fluorinated Carbohydrates, ACS Symposium Series 374, pp 78-108, American Chemical Society, Washington, DC.

Glaudemans, C. P. J., Jolley, M. E., \& Potter, M. (1973) Carbohydr. Res. 30, 409-413.

Gronenborn, A. M., \& Clore, G. M. (1982) Biochemistry 21, 4040-4048.

Hamer, G. K., Balza, F., Cyr, N., \& Perlin, A. S. (1976) Can. J. Chem. 56, 3109-3115.

Hartman, A. B., \& Rudikoff, S. (1982) EMBO J. 3, 3023-3030.

Hindsgual, O., Khare, D. P., \& Lemieux, R. U. (1985) Can. J. Chem. 63, 2653-2658.

Jolley, M. E., \& Glaudemans, C. P. J. (1974) Carbohydr. Res. 33, 377-382.

Kabat, E. A., Liao, J., Burzynska, H., Wong, T. C., Thøgersen, H., \& Lemieux, R. U. (1981) Mol. Immunol. 18, 873-891.

Keepers, J. W., \& James, T. L. (1984) J. Magn. Reson. 57, 404-426.

Kovăč, P., \& Glaudemans, C. P. J. (1984) J. Carbohydr. Chem. 3, 349-358.

Kovăč, P., Sokoloski, E. A., \& Glaudemans, C. P. J. (1984) Carbohydr. Res. 128, 101-109.

Lemieux, R. U., \& Koto, S. (1974) Tetrahedron 30, 1933-1951.

Lemieux, R. U., \& Bock, K. (1983) Arch. Biochem. Biophys. $221,125-134$.

Levy, H. R., Ejchart, A., \& Levy, G. C. (1983) Biochemistry 22, 2792-2796.

Macura, S., \& Ernst, R. R. (1980) Mol. Phys. 41, 95-117.

Marchessault, R. H., \& Perez, S. (1979) Biopolymers 18 (9), 2369-2374.

Marion, D., \& Wüthrich, K. (1983) Biochem. Biophys. Res. Commun. 113, 967-974.

Meyer, E. F., Jr., Clore, G. M., Gronenborn, A. M., \& Hansen, H. A. S. (1988) Biochemistry 27, 725-730.

Ohrui, H., Nishida, Y., Watanabe, M., Hori, H., \& Meguro, H. (1985) Tetrahedron Lett. 26, 3251-3254.

Ollo, R., Auffray, C., Sikorau, J. L., \& Rougeon, F. (1981) Nucleic Acids Res. 9, 4099-4109.

Pawlita, M., Potter, M., \& Rudikoff, S. (1982) J. Immunol. $129,615-618$.

Potter, M., \& Glaudemans, C. P. J. Methods Enzymol. 28, 388-395.

Rance, M., Bodenhausen, G., Wagner, G., Wüthrich, K., \& Ernst, R. R. (1985a) J. Magn. Reson. 62, 497-510.

Rance, M., Sørensen, O. W., Leupin, W., Kogler, H., Wüthrich, K., \& Ernst, R. R. (1985b) J. Magn. Reson. 61, 67-80.

Tainer, J. A., Getzoff, E. D., Alexander, H., Houghten, R. A., Olsen, A. J., \& Lerner, R. A. (1984) Nature 312, 127-134.

Vuk-Pavloviç, S., Blatt, Y., Glaudemans, C. P. J., Lancet, D., \& Pecht, I. (1978) Biophys. J. 24, 161-174.

Wong, T. C., Rutar, V., Wang, J.-S., Feather, M., \& Kovāč, P. (1984) J. Org. Chem. 49, 4358-4363. 